\title{
EDITORIAL PRINCIPLES AND PRACTICES
}

\section{Arrangement of Documents}

Documents are presented in chronological order according to the date of authorship of the original text. Enclosures and attachments to documents, however, do not appear in strict chronological sequence, but are printed with their original covering documents. Enclosures have been set in italic type in the table of contents for identification.

The publication date of news reports, speeches, and periodical articles is given on the place and date line within square brackets. In the case of news reports, speeches, and periodical articles containing the date of original composition, that date chronologically supersedes the date of eventual publication and is printed within double square brackets on the place and date line of the document.

Bureau of Investigation reports that give both the date of composition and the period covered by the report are arranged according to the date of composition.

Documents that lack dates and thus require editorial assignment of dates are placed in normal chronological sequence. When no day within a month appears on a document, it is placed after the documents specifically dated on the latest date within that month. Documents that carry only the date of a year are placed according to the same principle. Documents that cover substantial periods, such as diaries, journals and accounts, will appear according to the date of their earliest entries.

When two or more documents possess the same date, they are arranged with regard to affinity to the subject of the document that immediately precedes them or that which immediately follows them.

\section{Form of Presentation}

Each document is presented in the following manner:

A. A caption introduces the document and is printed in a type size larger than the text. Letters between individuals are captioned with the names 


\section{The Marcus Garvey and UNLA Papers}

of the individuals and their titles; captions, however, include a person's office only upon that person's first appearance. The original titles of published materials are retained with the documents; however, the headlines of some news reports are abbreviated or omitted, in which case this is indicated in the descriptive source note to the document.

B. The text of a document follows the caption. The copy text of letters or reports is taken from recipients' copies whenever possible, but in the absence of a recipient's copy, a file copy of the letter or report is used. If the file copy is not available, however, and a retained draft copy of the letter is found, the retained draft copy is used as the basic text.

C. Following the body of the text, an unnumbered descriptive source note describes editorially the physical character of the document by means of appropriate abbreviations. Moreover, a repository symbol gives the provenance of the original manuscript or, if it is rare, printed work. Printed sources are identified in the following manner:

I. A contemporary pamphlet is identified by its full title, place and date of publication, and the location of the copy used.

2. A contemporary essay, letter, or other kind of statement that appeared originally in a contemporary publication is preceded by the words "Printed in ...," followed by the title, date, and, in the case of essays, inclusive page numbers of the source of publication.

3. A contemporary printed source reprinted at a later date, the original publication of which has not been found, is identified with the words "Reprinted from ...," followed by the identification of the work from which the text has been reproduced. The same applies to any originally unpublished manuscript printed at a later date.

D. Numbered textual annotations that explicate the document follow the descriptive source note. The following principles of textual annotation have been applied:

1. Individuals are identified upon their first appearance, with additional information about them sometimes furnished upon their later appearance in a document where such data provide maximum clarification. Pseudonyms are identified, wherever possible, by a textual annotation.

2. Reasons for the assignment of dates to documents or the correction of dates of documents are explained in those instances where important historical information is involved.

3. Obscure allusions in the text are annotated whenever such references can be clarified.

4. Printed works and manuscript materials consulted during the preparation of textual annotations appear in parentheses at the end of each annotation. Frequently used reference works are cited in an abbreviated form, and the complete table may be found in the list of Abbreviations of Published Works. 
5. Garvey's appeal case (Marcus Gardey v. United States of America, no. 8317, Ct. App., 2d Cir., 2 February 1925) contains the complete transcript of his original mail fraud trial (United States of America v. Marcus Garpey et al., $\mathrm{C}_{31-37}$ and $\mathrm{C}_{33-688,}$ U.S. District Court, Southern District of New York, May 1923). Trial documents reprinted in the volume and references to the trial in annotations to documents are taken from the transcript used in the appeal case.

\section{Transcription of Text}

Manuscripts and printed material have been transcribed from the original text and printed as documents according to the following principles and procedures:

\section{A. Manuscript Material}

I. The place and date of composition are placed at the head of the document, regardless of their location in the original, but exceptions are made in the cases of certificates of vital registration and documents in which original letterhead stationery is reproduced. If the place or date of a letter (or both) does not appear in the original text, the information is supplied and printed in italics at the head within square brackets. Likewise, if either the place or date is incomplete, the necessary additional information is supplied in italics within square brackets. Superscript letters are brought down to the line of type, and terminal punctuation is deleted.

In the case of Bureau of Investigation reports that were submitted on printed forms, the place and date are abstracted and placed at the head of each document, while the name of the reporting agent is placed at the end of the document on the signature line. In the case of United States Postal Censorship reports, which were also prepared on printed forms, the narrative section of the report is printed in roman type. The other sections of the censorship reports, containing recorded analytic and filing information, have been treated as printed forms.

The formal salutation of letters is placed on the line below the place and date line, with the body of the text following the salutation.

The complimentary close of letters is set continuously with the text in run-in style, regardless of how it was written in the original.

The signature, which is set in capitals and small capitals, is placed at the right-hand margin on the line beneath the text or complimentary close, with titles, where they appear, set in uppercase and lowercase. Terminal punctuation is deleted. 
When a file copy of a document bearing no signature is used to establish the text but the signatory is known, the signature is printed in roman type within square brackets.

The inside address, if significant and not repetitive, is printed immediately below the text.

Endorsements, docketings, and other markings appearing on official correspondence, when intelligible, are reproduced in small type following the address, with appropriate identification. In the case of other types of documents, such as private correspondence, endorsements and dockets are reprinted only when they are significant.

Minutes, enclosures, and attachments are printed in roman type following their covering documents and placed after the annotation material of their covering documents. Whenever minutes, enclosures, or attachments are not printed, this fact is always recorded and explained. Whenever a transmission letter originally accompanying an enclosure or attachment is not printed, the omission is noted and the transmission document identified and recorded in the descriptive source note.

2. Printed letterheads and other official stationery are not reproduced, unless they contain significant information, in which case they are reprinted above the date line. In cases where they are not reprinted, they are sometimes abstracted, and the information is placed in the descriptive source note. Printed addresses are reproduced only upon the first appearance.

3. In general, the spelling of all words, including proper names, is preserved as written in the manuscript and printed sources. Thus, personal and place names that are spelled erratically in the original texts are regularized or corrected only in the index. However, serious distortion in the spelling of a word, to such an extent as to obscure its true meaning, is repaired by printing the correct word in italics within square brackets after the incorrect spelling. Mere "slips of the pen" or typographical errors are corrected within the word and printed in roman type within square brackets; however, some typographical errors that contribute to the overall character of the document are retained.

4. Capitalization is retained as in the original. Words underlined once in a manuscript are printed in italics. Words that are underlined twice or spelled out in large letters or full capitals are printed in small capitals.

5. Punctuation, grammar, and syntax are retained as found in the original texts. In the case of punctuation, corrections that are essential to the accurate reading of the text are provided within square brackets. 


\section{Edtrorial Principles and Practices}

If, however, a punctuation mark appears in a document as a result of typographical error, it is corrected in square brackets or, in some instances, silently deleted.

6. All contractions and abbreviations in the text are retained. Abbreviations of titles or organizations are identified in a list of abbreviations that appears at the front of the volume. Persons represented by initials only will have their full names spelled out in square brackets after each initial on their first appearance.

7. Superscript letters in the text are lowered and aligned on the line of print.

8. Omissions, mutilations, and illegible words or letters have been rendered through the use of the following textual devices:

a) Blank spaces in a manuscript are shown as [ ]. If the blank space is of significance or of substantial length, this fact is elaborated upon in a textual annotation.

b) When a word or words in the original text must be omitted from the printed document because of mutilation, illegibility, or omission, the omission is shown by the use of ellipses followed by a word or phrase placed in square brackets in italics, such as: ... [torn], ... [illegible], .. [ [remainder missing].

c) Missing or illegible letters of words are represented by suspension points within square brackets, the number of points corresponding to the estimated number of letters omitted. The same holds true for missing or illegible digits of numbers.

d) All attempts have been made to supply conjecturally missing items in the printed document, according to the following rules:

(I) if there is no question as to the word, the missing letter is supplied silently;

(2) if the missing letter(s) can only be conjectured, the omission is supplied within square brackets and printed in roman type. Uncertainty of the conjecture, however, is indicated by a question mark within the square brackets in the document.

9. Additions and corrections made by the author in the original text have been rendered as follows:

a) Additions between the lines are brought onto the line of type and incorporated into the body of the text within diagonal lines / /

b) Marginal additions or corrections by the author are also incorporated into the printed document and identified by the words [in the margin] italicized in square brackets. Marginal notes made by someone other than the author are treated as an endorsement and are printed following the text of the document.

c) Words or groups of words deleted in the original, as in a draft, are restored in the printed document. The canceled word or phrase is 


\section{The Marcus Garvey and UNIA papers}

indicated by canceled type at the place where the deletion occurs in the original text. If a lengthy deletion is illegible, this is indicated by the words [deletion illegible].

\section{B. Printed Material}

Contemporary printed material has been treated in the same manner as were original texts and has been transcribed according to the same editorial principles as was manuscript material.

I. In the case of originally published letters, the place and date of composition are uniformly printed on the place and date line of the document, regardless of where they appear in the original, and placed within double square brackets. Those elements that have been editorially supplied are italicized.

2. Newspaper headlines and subheads are printed in small capitals. Headlines are punctuated as they are in the original; however, they are reproduced in the printed document in as few lines as possible. Unless the headline would otherwise become distorted, ornamental lines appearing within the headlines are not retained.

3. Words originally printed in full capitals for emphasis or for other reasons are usually printed in small capitals. Boldfaced type that appears within the text is retained.

4. The signature accompanying a published letter is printed in capitals and small capitals.

s. Obvious typographical errors and errors of punctuation, such as the omission of a single parenthesis or quotation mark, are corrected and printed within square brackets in roman type.

6. In the case of a printed form with spaces to be filled in, the printed words are designated in small capitals, while the handwritten or typewritten insertions are designated in italics with spaces left before and after the small capitals to suggest the blank spaces in the original form. 